\title{
The effectiveness of non-pharmacological or non- surgical interventions on the Health Related Quality of Life of People with Parkinson's Disease: a protocol of systematic review of randomized controlled trials
}

\section{Tamara Cristine de Paula ( $\nabla$ tamara.musicoterapia@gmail.com )}

Federal University of Goias: Universidade Federal de Goias https://orcid.org/0000-0002-6965-5844

\section{Tereza Raquel de Melo Alcântara-Silva}

Federal University of Goias: Universidade Federal de Goias

\section{Leonardo Francisco Citon}

Universidade Federal do Rio de Janeiro

Celmo Celeno Porto

Universidade Federal de Goias

\section{Protocol}

Keywords: Health-Related Quality of Life, Parkinson's Disease, Elderly Peoples

Posted Date: February 11th, 2021

DOI: https://doi.org/10.21203/rs.3.rs-215111/v1

License: (9) This work is licensed under a Creative Commons Attribution 4.0 International License. Read Full License 


\section{Abstract}

Background: Parkinson's disease (PD) is the second most common neurodegenerative, progressive and disabling disease affecting the elderly population, with by motor and non-motor symptoms that interfere with the Health-Related Quality of Life (HRQoL) of this population. Currently, there are still no resources to cure the disease, so the main treatment method used to reduce symptoms is based initially on pharmacological therapy, and in some cases, surgery is recommended. However, some unconventional interventions have been used, showing good results for the improvement of symptoms that also include HRQoL. Therefore, this investigation aimed to identify non-pharmacological or non-surgical interventions, in randomized clinical studies (RCTs) and their effectiveness in improving the HRQoL of people with PD.

Methods: Systematic review, guided by the PRISMA method, using the SciELO, MEDLINE / PubMed, Cochrane Library, Web of Science, Scopus, and Brazilian Digital Library of Theses and Dissertations databases - BDTD, through CAFe Access on the CAPES / MEC Journals portal. "Quality of Life" "Parkinson's Disease" - "Randomized Controlled Trial", were the keywords used. Articles were selected by 2 independent reviewers using a third for doubts / discrepancies. Articles published until October 2020, in languages English, Portuguese and Spanish, RCTs, with non-pharmacological or non-surgical interventions, population diagnosed with PD, at any age or stage of the disease will be included. A narrative synthesis will be used to summarize the results and discussion, as well as a methodological evaluation of the RCTs using Cochrane Collaboration's risk of bias tool.

Discussion: This review will identify the effectiveness of non-pharmacological and non-surgical interventions aimed at improving the HRQoL of people with PD, based on assessment instruments related to the proposed theme, based on RCT. Therefore, the findings show the current panorama of studies performed, discussion about their clinical applicability, as well as suggestions for improvements of future trials.

Registration of Systematic Review: CRD42021221383

\section{Backgroud}

Global development brings important changes with regard to the increasing longevity of human populations, the process of which can be accompanied by chronic diseases that, in most cases, compromise the Health Related Quality of Life (HRQoL) of the aged (1). Among the most common diseases of aging is Parkinson's disease (PD), the second most common neurodegenerative disease, with a higher prevalence among the elderly $(1,2)$. The diagnosis of PD is based mainly on the motor symptoms that make up the classic tetrad, which are rest tremor, rigidity, bradykinesia, and postural instability (1-3). Non-motor symptoms are present in PD and can appear even before the initial diagnosis. Among the most frequent are anxiety, depression, sleep disorders, cognitive changes, and fatigue $(4,5)$. Both motor and non-motor symptoms, associated or not, significantly compromise the individual's life, and with the evolution of the disease they mainly contribute to the worsening of HRQoL $(6,7)$, primarily the aspects that 
refer to assessing parts of everyday life (8), meaning the way the individual perceives the impact of his health or illness on physical, mental and social aspects of their life (9).

The treatment of PD, whether pharmacological and / or surgical, aims to improve symptoms, especially motor symptoms. Non-pharmacological interventions can be used with drug and / or surgical treatments and have shown promising therapeutic responses with regard to delaying the evolution of the disease and improving HRQoL, as observed in randomized clinical trials $(5,10,11)$.

This review concerns randomized clinical trials related to non-pharmacological interventions aimed at improving HRQoL identified through assessments of specific domains related to the topic, and instruments adopted to assess HRQoL of people with PD will be discussed.

\section{Methods}

The protocol used in the present study was structured according to the guidelines of the Preferred Reporting Items for Systematic Reviews and Meta-Analyzes checklist - PRISMA (12), in Additional files 1 , registered in the international prospective of systematic reviews - PROSPERO, under the number CRD42021221383. The selection of articles followed the PICOS criteria: Population, people diagnosed with Parkinson's Disease, at any age, of both sexes, at any stage of the disease; the intervention chosen was the non-pharmacological or non-surgical; Comparison, participants who received any type of non-drug intervention; Outcomes related to the impact of the proposed interventions on HRQoL and; Study design restricted to randomized controlled trials (RCTs), with a date limit of publication of October 2020. Also, to be included, the study should specify the type of intervention used, with a description of the duration and frequency of the sessions, as well as the mention of the domains evaluated and their respective results, obtained through assessment instruments, generic or specific for HRQoL. Duplicate publications, studies in progress, abstracts of works published in scientific events and which did not have any of the established keywords in the title were excluded.

\section{Search Strategy}

SciELO, MEDLINE / PubMed, Cochrane Library, Web of Science, Scopus, and gray literature databases at the Brazilian Digital Library of Theses and Dissertations - BDTD, through CAFe Access and the CAPES / MEC Journals portal, were used to select articles, published in English, Portuguese and Spanish, up to October 2020, using the keywords "Quality of Life" - "Parkinson Disease" - "Randomized Controlled Trial" combined with the relevant related synonyms, suggested by querying terms in DeCS and MeSH.

\section{Data Extraction}

The eligibility assessment was carried out independently and standardized by two reviewers and a third in case of doubt or disagreement about the eligibility, by discussion and agreement. The initial search combined, in each database, the OR Boolean between each descriptor and related synonym, and AND for the combination of the results obtained in the searches by descriptor, as shown in Table 1. Three tests of relevance (TR) were created and applied to the articles, after initial identification and removal of 
duplicates, TR1 being used to evaluate the titles, TR2 for evaluating abstracts, and TR3 for analyzing the full article. To manage the organization of the references for each step described, a database was created in Clarivate's EndNote 20.

\begin{tabular}{|c|c|c|}
\hline Data Bases & Terms & Results \\
\hline MEDLINE/Pubmed & $\begin{array}{l}\text { ("Quality of Life"[Title/Abstract] OR "HRQOL"[Title/Abstract] OR } \\
\text { "Health Related Quality of Life"[Title/Abstract]) AND "clinical trial" } \\
\text { [Publication Type] AND (("Parkinson Disease"[Title/Abstract] OR } \\
\text { "Idiopathic Parkinson's disease"[Title/Abstract] OR "Parkinson's } \\
\text { disease"[Title/Abstract] OR "Primary Parkinsonism" } \\
\text { [Title/Abstract]) AND "clinical trial"[Publication Type]) AND } \\
\text { (("Randomized Controlled Trial"[Title/Abstract] OR "Randomized } \\
\text { Controlled Clinical Trials"[Title/Abstract]) OR "clinical trial" } \\
\text { [Publication Type]) }\end{array}$ & 92 \\
\hline
\end{tabular}

$\begin{array}{ll}\text { Scopus } & \text { ((TITLE-ABS-KEY ("Quality of Life") OR TITLE-ABS-KEY ("HRQOL") } \\ & \text { OR TITLE-ABS-KEY ("Health Related Quality of Life"))) AND } \\ & \text { ((TITLE-ABS-KEY ("Doença de Parkinson") OR TITLE-ABS-KEY } \\ & \text { ("Doença de Parkinson idiopática") OU TITLE-ABS-KEY ("doença } \\ & \text { de Parkinson") OR TITLE-ABS-KEY ("Paralisia Agitada") OU TITSLE- } \\ & \text { ABS-KEY ("Parkinsonismo primário"))) AND ((TITLE-ABS-KEY } \\ & \text { ("Randomized Controlled Trial") OR TITLE-ABS-KEY ("Randomized } \\ & \text { Controlled Clinical Trials"))) }\end{array}$

Web of Science TS=((Quality of Life) OR (HRQOL) OR (Health Related Quality of Life) $)$ AND TS $=(($ Parkinson Disease $)$ OR (Idiopathic Parkinson's disease) OR (Parkinson's disease) OR (Agitated Paralysis) OR (Primary Parkinsonism)) AND TS $=(($ Randomized Controlled Trial) OR (Randomized Controlled Clinical Trials))

Scielo

(ti:("Quality of Life")) OR (ti:("HRQOL")) OR (ti:("Health Related Quality of Life")) AND (ti:("Parkinson Disease")) OR (ti:("Idiopathic Parkinson's disease" )) OR (ti:("Parkinson's disease")) OR (ti: ("Agitated Paralysis")) OR (ti:("Primary Parkinsonism")) AND (ti: ("Randomized Controlled Trial" )) OR (ti:("Randomized Controlled Clinical Trials"))

("Quality of Life"):ti,ab,kw OR ("HRQOL"):ti,ab,kw OR ("Health

Cochrane Library BDTD - Brazilian Digital Library of Theses and Dissertations databases
Related Quality of Life"):ti,ab,kw AND ("Parkinson

Disease"):ti,ab,kw OR ("Idiopathic Parkinson's disease"):ti,ab,kw

OR ("Parkinson's disease"):ti,ab,kw OR ("Agitated

Paralysis"):ti,ab,kw OR ("Primary Parkinsonism"):ti,ab,kw AND

("Randomized Controlled Trial"):ti,ab,kw OR ("Randomized Controlled Clinical Trials"):ti,ab,kw

(Title:"Quality of Life" AND Title:"HRQOL" AND Title:"Health

Related Quality of Life" AND Title:"Parkinson Disease" AND

Title:"Idiopathic Parkinson's disease" AND Title:"Parkinson's disease" AND Title:"Agitated Paralysis" AND Title:"Primary Parkinsonism" AND Title:"Randomized Controlled Trial" AND Title:"Randomized Controlled Clinical Trials") (Title:"Quality of Life" AND Title:"Parkinson Disease" AND Title:"Randomized Controlled Trial") 


\section{Risk of Bias}

To assess the Risk of Bias (RoB) of the studies, the tool RevMan version 5.4.1, developed by Cochrane Collaboration, was used (13). This tool assesses seven items related to the randomization process, blinding and other risk factors for bias: "Random sequence generation (selection bias)", "Allocation concealment (selection bias)", "Blinding of participants and personnel (performance bias)", "Blinding of outcome assessment (detection bias)", "Incomplete outcome data (attrition bias)", "Selective reporting (reporting bias)", "Other bias". For each selected study, the author must answer the questions choosing one of the answers "Low Risk", "Unclear Risk" and "High Risk" and justify the reason for the choice.

\section{Synthesis of the evidence}

The synthesis of the evidence found was analyzed and consolidated in Table 2 in order to meet the objectives of this study. This information depicts criteria such as author, year of publication, study design, country of origin, general objective of the study, average age of the participants, size of the sample studied, frequency of interventions, HRQoL assessment instruments used and results obtained related to HRQoL.

\section{Results}

\section{Selection of Studies}

Initially, 1,988 records were identified in the databases. Of these, 838 were excluded due to being duplicates, leaving 1,150 for the next stage, in which, after reading the titles, 1,129 publications were excluded by TR1 and another five after reading the abstracts, as provided for in TR2. After this step, 16 records remained, which were added to two results found in the manual search, bringing the total to 18 articles. Of these 18, the two articles in the manual search were excluded due to being duplicates, leaving 16 articles once again, which after fully reading, 8 were excluded by TR3, and 1 because they included other parkinsonian syndromes, which had not been mentioned in the title or in the abstract. At the end of the stages, seven studies were chosen for the qualitative synthesis of the data, as shown in a Fig. 1. 
Table 2 - Results

Method

Author $\quad$ Objective
(s)/ Year/
Study
Design

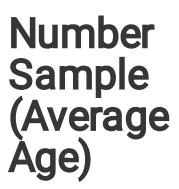

$\mathrm{N}: 40$

(IG:

$67.3 \pm 6.39$;

CG:

$68.60 \pm 7.32)$

\section{Results}

\section{Type of Intervention \\ HRQoL assessment tool}

Times per week / study duration
IG: Mindfulness/2 PQD-39 $\mathrm{h} / 8 \mathrm{w}$

CG: Lectures on PD $/ 1 \mathrm{~h} / 8 \mathrm{w}$.

\section{(2)}

Ayrmlou et al, 2020/

RCT

\section{Assess}

stress level and HRQoL after training in

Mindfulness
General score:

Lowest average score for IG compared to CG; significant difference for the social support domain (34.13 \pm 9.7 vs 26.19 \pm 7.7 for the control and experimental groups, respectively. $\mathrm{P}$ $=0.007$ ).

$\begin{array}{lll}\text { (14) Poier } & \begin{array}{l}\text { Compare the } \\ \text { influence of }\end{array} & \mathrm{N}: 29 \\ \text { et al., } & \text { Argentine } & \text { (IG: } \\ \text { 2019/ } & \text { tango with } & 68.50 \pm 8.07 ; \\ \text { RCT } & \text { Tai Chi on } & \text { CG: } \\ & \text { HRQoL } & 68.87 \pm 10.96)\end{array}$

IG: Tango/1h/10w PQD-39

CG: TC/1h/10w.
General score: no improvement for IG and CG

Improvement for tango group in relation to

emotional wellbeing $(p=$ 0.039) after 10 weeks of intervention compared to the Tai Chi group.

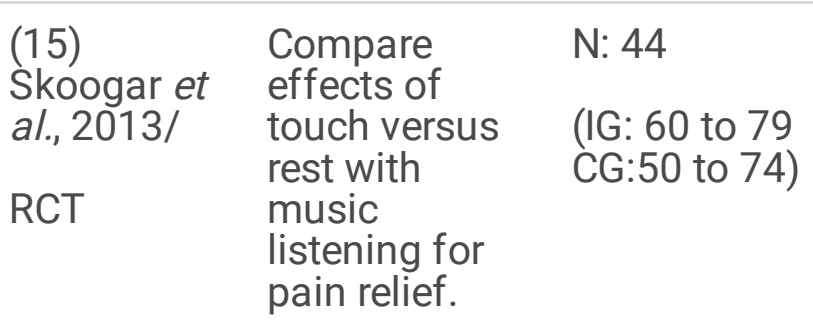

\begin{tabular}{|c|c|c|}
\hline $\begin{array}{l}\text { IG: TT / 1h / 8w } \\
\text { CG: RTM / 1H / 8w. }\end{array}$ & SF-36 & $\begin{array}{l}\text { General score: } \\
\text { significant } \\
\text { improvement } \\
\text { for both } \\
\text { groups. }\end{array}$ \\
\hline & & $\begin{array}{l}\text { Analysis } \\
\text { between } \\
\text { groups (IG and } \\
\text { CG) in the } \\
\text { physical } \\
\text { aspects item } \\
\text { (CG } 32.0 \text { and IG } \\
38.4=p<0.05 \text { ) } \\
\text { and social }\end{array}$ \\
\hline
\end{tabular}




\begin{tabular}{|c|c|c|c|c|c|}
\hline & & & & & $\begin{array}{l}\text { functioning } \\
\text { item (CG 16.1 } \\
\text { and IG } 21.3=p \\
<0.05 \text { ) after } 4 \\
\text { weeks of } \\
\text { intervention }\end{array}$ \\
\hline $\begin{array}{l}\text { (8) Tickle- } \\
\text { Degnen et } \\
\text { al., } \\
\text { 2010/ } \\
\text { RCT }\end{array}$ & $\begin{array}{l}\text { Investigate } \\
\text { whether } \\
\text { HRQoL can } \\
\text { improve self- } \\
\text { management } \\
\text { intervention } \\
\text { time. }\end{array}$ & 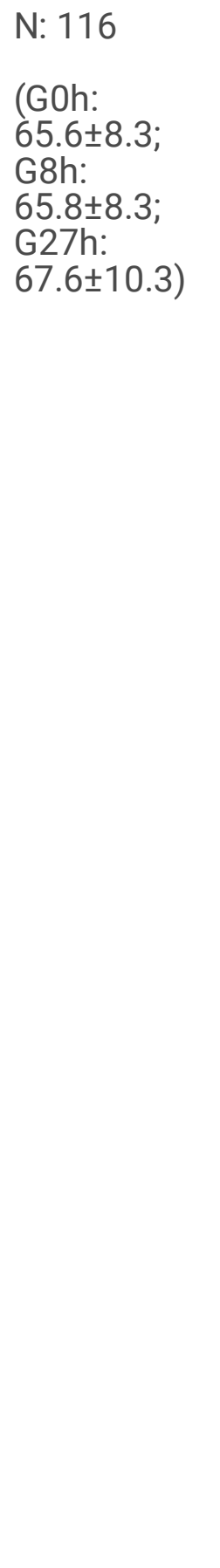 & $\begin{array}{l}\text { G0h: without } \\
\text { intervention } \\
\text { G18h: self- } \\
\text { management } \\
\text { rehabilitation / 3h } \\
\text { (group in office) + } \\
\text { 1h30min (social } \\
\text { group)/6w } \\
\text { G27h: self- } \\
\text { management } \\
\text { rehabilitation / } \\
4 \text { h30m / } 2 \text { sessions } \\
\text { of } 1 \mathrm{~h} 30 \text { min } \\
\text { (consulting group) } \\
+1 \mathrm{~h} 30 \text { min (home } \\
\text { group) / 6w }\end{array}$ & PQD-39 & $\begin{array}{l}\text { - Improvement } \\
\text { demonstrated } \\
\text { after } 6 \text { weeks } \\
\text { of intervention } \\
\text { (eta }=0.23, \mathrm{Cl}= \\
0.05 \text { - } 0.40, \mathrm{p}= \\
0.01 \text { ), } \\
\text { persisting in } \\
\text { the follow-up } \\
\text { assessment. } \\
\text { - In the } \\
\text { comparative } \\
\text { analysis } \\
\text { between } 18 \mathrm{~h} \\
\text { and } 27 \mathrm{~h}, \mathrm{no} \\
\text { significant } \\
\text { difference was } \\
\text { observed. } \\
\text { - Clinical } \\
\text { improvement } \\
\text { was observed } \\
\text { in the } \\
\text { comparison } \\
\text { between the } \\
18 \mathrm{~h} \text { and } 27 \mathrm{~h} \\
\text { groups and the } \\
\text { group without } \\
\text { intervention } \\
\text { (0h). } \\
\text { - Significant } \\
36 \% \text { difference } \\
\text { in rates (95\% Cl } \\
=20 \% \text { to } 52 \% \\
\text { difference) in } \\
\text { relation to the } \\
\text { communication } \\
\text { and mobility } \\
\text { domains } \\
\text { (p <0.05). }\end{array}$ \\
\hline $\begin{array}{l}\text { (16) } \\
\text { Theodoros } \\
\text { et al., } \\
2016 / \\
\text { RCT }\end{array}$ & $\begin{array}{l}\text { Compare } \\
\text { intensive in- } \\
\text { person } \\
\text { speech } \\
\text { treatment } \\
\text { with face-to- } \\
\text { face online } \\
\text { treatment. }\end{array}$ & $\begin{array}{l}\text { N: } 52 \\
\text { (FTFG: } \\
72.86 \pm 9.99 \\
\text { MOG: } \\
71.62 \pm 7.77 \\
\text { NMOG: } \\
69.19 \pm 8.60)\end{array}$ & $\begin{array}{l}\text { FTFG: 4h / 4w } \\
\text { (office) } \\
\text { MOG and NMOG } \\
\text { (not randomized): } \\
4 \mathrm{~h} / 4 \mathrm{w} \text { (home) }\end{array}$ & PQD-39 & $\begin{array}{l}\text { The non- } \\
\text { inferiority of } \\
\text { online } \\
\text { treatment was } \\
\text { confirmed } \\
\text { through } \\
\text { comparable } \\
\text { clinical and } \\
\text { quality of life } \\
\text { results for }\end{array}$ \\
\hline
\end{tabular}




\begin{tabular}{|c|c|c|c|c|c|}
\hline & & & & & $\begin{array}{l}\text { metropolitan } \\
\text { groups } \\
\text { between online } \\
\text { and face-to- } \\
\text { face treatment. } \\
\text { Significant } \\
\text { post-treatment } \\
\text { improvements } \\
\text { were achieved } \\
\text { in quality of life } \\
\text { between } \\
\text { groups. No } \\
\text { significant } \\
\text { effects of } \\
\text { online } \\
\text { treatment } \\
\text { related to } \\
\text { location have } \\
\text { been identified. }\end{array}$ \\
\hline $\begin{array}{l}\text { (5) } \\
\text { Barboza et } \\
\text { al., 2019/ } \\
\text { RCT }\end{array}$ & $\begin{array}{l}\text { To evaluate } \\
\text { the effects of } \\
\text { physical } \\
\text { therapy } \\
\text { associated } \\
\text { with } \\
\text { cognitive } \\
\text { training to } \\
\text { improve } \\
\text { cognition } \\
\text { and HRQoL. }\end{array}$ & $\begin{array}{l}\text { N: } 54 \\
\text { (IG: } \\
64.33 \pm 7.77 \\
\text { CG: } \\
67.11 \pm 8.14)\end{array}$ & $\begin{array}{l}\text { IG. Cognition Motor } \\
\text { Group (CMG) } \\
\text { received the } \\
\text { treatment of MG }+ \\
\text { cognitive } \\
\text { stimulation/3h/16w } \\
\text { CG: Motor Group } \\
(\mathrm{MG}) / 3 \mathrm{~h} / 16 \mathrm{w}\end{array}$ & PDQL & $\begin{array}{l}\text { Intragroup } \\
\text { analysis: } \\
\text { improvement } \\
\text { of cognitive } \\
\text { functions } \\
\text { (memory and } \\
\text { visuospatial } \\
\text { function } \\
\text { domains) and } \\
\text { HRQoL, without } \\
\text { statistical } \\
\text { significance. }\end{array}$ \\
\hline $\begin{array}{l}\text { (17) Ribas } \\
\text { et al., } \\
2017 / \\
\text { RCT }\end{array}$ & $\begin{array}{l}\text { Analyze the } \\
\text { effectiveness } \\
\text { of } \\
\text { exergaming } \\
\text { in improving } \\
\text { functional } \\
\text { balance, } \\
\text { fatigue, } \\
\text { functional } \\
\text { exercise } \\
\text { capacity, and } \\
\text { QOL }\end{array}$ & $\begin{array}{l}\text { N: } 20 \\
(C G: \\
60.20 \pm 11.29 \text {; } \\
\text { IG: } \\
61.70 \pm 6.83)\end{array}$ & $\begin{array}{l}\text { IG: Exergaming with } \\
\text { video games / } 1 \mathrm{~h} / \\
12 \mathrm{w} \\
\text { CG: physical } \\
\text { activity (stretching, } \\
\text { active and } \\
\text { resistance } \\
\text { exercises)/1h/12w }\end{array}$ & PQD-39 & $\begin{array}{l}\text { There were no } \\
\text { differences in } \\
\text { quality of life } \\
\text { between the } \\
\text { two groups } \\
\text { after } 12 \text { weeks } \\
\text { of treatment. }\end{array}$ \\
\hline
\end{tabular}

The total number of participants was 355 people, aged between 56 and 80 years old, of both sexes (224 women and 131 men), coming from outpatient clinics at Universities or Neurology Medical Departments, with a diagnosis of PD certified by a neurologist, with stage of the disease between I and III according to the Hoehn \& Yahr scale (18), which remained, during the research, in ON state without recent alterations, with preserved cognitive functions, independent locomotion, and without participation in any other modality of therapy, which was similar to the baseline of the samples. 
The RoB of the studies included of this review, as shown in figure 2 and figure 3 , showed, in general, low risk. However, an inconclusive bias was detected for the items "Blinding of participants and personnel (performance bias)" $(2,8,13,14,16)$ and "Blinding of outcome assessment (detection bias)" $(5,15)$. For the items "Allocation concealment (selection bias)" $(2,13,14)$ and "hidden allocation of participants" (13, 14) high risk was detected in the studies.

Regarding the evaluation, the instruments chosen were Parkinson Disease Questionnaire - PDQ-39 (19); Parkinson's Disease Quality of Life - PDQL (20), specific evaluative instruments for PD, and a generic SF36 (21). About of the duration of the studies, varied from $1-2,5$ months $(2,14,16), 3$ to 7,5 months $(5,8$, 17), and 8 and a half months (15).

\section{Discussion}

The present review focused on identifying possible non-pharmacological and non-surgical interventions aimed at improving the HRQoL of people with PD, whose outcomes have been observed from evaluative instruments related to the proposed theme, and presented in RCT. These results suggest that interventions used in the included studies positively influenced the HRQoL of participants, in general, and levels of significance for some specific domains (Communication, Mobility, Social Support, Emotional Well-being, Physical Aspects). These findings led to reflections on some aspects that are important to clinical practice.

Initially, the importance of RCTs was highlighted, since their experimental design modality is considered the gold standard among studies. Their advantage over other experimental models is the presence of a control group that allows for the evaluation and demonstration of the cause-and-effect relationship between a set of independent and dependent variables, thus increasing the level of confidence of those found (22).

Still, the adequate selection of the evaluation instruments is of remarkable recognition and value, preferably those specific to the context under analysis, as these can produce results that are closer and more reliable to the reality under study (23). On this subject, the present review showed that, despite the majority of studies using specific HRQoL questionnaires for PD, some researchers choose general assessment instruments.

About of the types of interventions used in the included studies, it was possible to observe that regardless of the way they were conducted - whether exclusively or associated with other modalities, or even if they were conducted by the therapist or self-administered by the patient under the professional's guidance they provided an improvement in the quality of life of the participants, as demonstrated in the general scores of the scales used to assess HRQoL, and also that some domains showed statistical significance. In this sense, it is understood that different modalities of non-pharmacological intervention can be introduced in the therapeutic regimens of people with PD and some benefits beyond the patient's therapeutic needs can be associated with them, considering that the possibility of expanding the repertoire of interventions allows the therapist the option to select those most appropriate to the context and proposed therapeutic objectives, thus leading to a more patient-centered treatment (24). These aspects 
favor the establishment and strengthening of the therapist-patient bond, which is essential for the development of the therapeutic process.

In this same context, a wide repertoire of interventions can be open to the patient, when possible, with the opportunity to choose between those they like the best. This contributes to greater adherence and collaboration with treatment, helps to improve or maintain the ability to choose, the level of independence and autonomy, self-esteem, among others and, as possible results, better responses to treatment, especially regarding motor aspects, and emotional and social relationships that maintain a close relationship with HRQoL and vice versa (25). Also worthy of consideration were the levels of statistical significance related to the best HRQoL (27) regarding the domains "Communication", "Mobility", "Social Support", "Emotional Well-being", "Physical Aspects", as presented in the included studies. Regarding their relationship with HRQoL, there is no doubt. However, it is worth highlighting the significance of these results, in some cases favoring group sessions, and provides openings for patients to carry out, at times, the self-management of interventions, monitored by the therapist, as this training develops beyond social skills, an important aspect to improve HRQoL (26), commonly impaired in PD patients.

\section{Conclusion}

This systematic review concludes that:

- Non-pharmacological interventions can and should be part of the treatment protocols for people with Parkinson's disease, because they help to minimize motor and non-motor symptoms and consequently improve the HRQoL of these individuals, due to the close relationship between them.

- Professionals are made aware of the importance of committing themselves to systematic and regular monitoring of the HRQoL of the patient under treatment.

- HRQoL assessment instruments, especially those specific to PD, are part of the routine, at the same frequency as the assessments of other parameters and are included in all phases (pre, during and post treatment), considering the bidirectional influence between HRQoL and the symptoms that are part of the disease.

- Future studies need to be carried out, as this is an aspect that can have negative impacts on the life and treatment, in general, of the person with PD.

\section{Limitations}

The main limitations of this systematic review presented here, proposed to analyze RCT data on nonpharmacological interventions to improve the quality of life of people with PD, are related to the lack of similarity between the methodological designs, which favors the comparison of outcomes. Another limitation refers to the lack of detail in descriptions of the interventions, since their absence makes it difficult to understand, to interpret the procedures adopted, and to replicate studies in academic and clinical spheres. Finally, the reduced number of publications restricts a more consistent analysis. 


\section{Abbreviations}

PD - Parkinson's Disease; HRQoL - Health-Related Quality of Life; RCTs - Randomized Controlled Trial; PRISMA - for Systematic Reviews and Meta-Analyzes checklist ; BDTD - Brazilian Digital Library of Theses and Dissertations databases; CAFe - Federated Academic Community - ; CAPES - Coordination for the Improvement of Higher Education Personnel; MEC - Ministry of Education and Culture; QoL - Quality of Life; TR 1 - Test of Relevance 1; TR 2 - Test of Relevance 2; TR 3 - Test of Relevance 3; ABS - Abstract; TI Title; AB; Abstract; KW - Key Words; RoB - Risk of Bias; RevMan - Review Magager; PDQ - 39 - Parkinson's Disease Questionnaire; PDQL - Parkinson's Disease Quality of Life Questionnaire; SF- Short Form Health Survey 36; h - hour; IG - Intervention Group; CG - Control Group; FTFG- Face to Face Group; MOG Metro Online Group; NMOG-Non-Metro Online Group; TG CMG - Cognition Motor Group; MG - Motor Group; w week; $h$ hour, RTM-Rest to Music.

\section{Declarations}

\section{Acknowledgements}

Not applicable

\section{Authors' contributions}

The study was created by TCP and TRMAS. TCP (as the first reviewer), has conducted searches in the databases, and with LFC (as the second reviewer), have carried out the screening and full reading of the articles. Both were supported by TRMAS (third reviewer) when necessary. CCP and TRMAS have provided guidance on methodological development and participation in the writing of the protocol with TCP and LFC.

\section{Funding}

Not applicable

\section{Availability of data and materials}

All data generated or analysed during this study are included in this published article.

\section{Ethics approval and consent to participate}

Not applicable

\section{Consent for publication}

Not applicable

\section{Competing interests}


The authors declare that they have no competing interests.

\section{Author details}

${ }^{1}$ Faculty of Medicine, Federal University of Goiás, SECRETARIA - 1a. s/n - S. Universitário, Goiânia - Goiás CEP 74605-020 Brasil, ${ }^{2}$ School of Music and Performing Arts, Federal University of Goiás, Goiânia, Brazil, ${ }^{3}$ Brazilian Conservatory of Music, Federal University of Rio de Janeiro, Rio de Janeiro, Brazil.

\section{References}

1. Teixeira-Machado L, Araújo FM, Cunha FA, Menezes M, Menezes T, DeSantana JM. Feldenkrais method-based exercise improves quality of life in individuals with Parkinson's disease: A controlled, randomized clinical trial. Altern Ther Health Med. 2015; doi:10.1016 / j.jpain.2015.01.471

2. Ayromlou H Ranjbar F, Ghaemian N, Rikhtegar R NS. The Impact of Mindfulness on Quality of Life in Parkinson's Disease: (A RandomizedClinical Trial). Britsh Journal of Medical Practitioners. 2020. https://www.bjmp.org/content/impact-mindfulness-quality-life-parkinson-s-disease-randomizedclinical-trial. Acessed 20 Nov 2020.

3. Armstrong MJ, Okun MS. Diagnosis and Treatment of Parkinson Disease: A Review. 2020; doi.org/10.1001/jama.2019.22360.

4. Ferreira RM, Alves W, de Lima TA, Alves TGG, Alves Filho PAM, Pimentel CP, et al. The effect of resistance training on the anxiety symptoms and quality of life in elderly people with Parkinson's disease: a randomized controlled trial. 2018; doi.org/10.1590/0004-282x20180071.

5. Mariano Barboza N, Brandão Terra M, Brandão Bueno ME, Christofoletti G, Smaili SM. Physiotherapy Versus Physiotherapy Plus Cognitive Training on Cognition and Quality of Life in Parkinson Disease: randomized Clinical Trial. 2019; doi: 10.1097 / PHM.0000000000001128

6. Poewe W, Seppi K, Tanner CM, Halliday GM, Brundin P, Volkmann J, et al. Parkinson disease. 2013; doi: 10.1038 / nrdp.2017.13.

7. Limongi JCP, Limongi JCP. Quality of life in Parkinson's disease. 2017; doi:10.1590/0004$282 \times 20170114$.

8. Tickle-Degnen L, Ellis T, Saint-Hilaire MH, Thomas CA, Wagenaar RC. Self-management rehabilitation and health-related quality of life in Parkinson's disease: a randomized controlled trial. 2010; doi:10.1002/central/CN-00750337/full.

9. Balash Y, Korczyn AD, Migirov AA, Gurevich T. Quality of life in Parkinson's disease: A gender-specific perspective. 2019; doi: 10.1111 / ane.13095.

10. Cancela JM, Mollinedo I, Montalvo S, Vila Suárez ME. Effects of a High-Intensity Progressive-Cycle Program on Quality of Life and Motor Symptomatology in a Parkinson's Disease Population: A Pilot Randomized Controlled Trial. 2020; doi: 10.1089 / rej.2019.2267.

11. Araújo J, Valois É, Cruz M. Desenhos de estudos epidemiológicos boca-dividida e paralelo: uma revisão da literatura. Revistas. 2016 Apr 28;73:60. 
12. An Editorial from the Editors-in-Chief of Systematic Reviews details why this checklist was adapted Moher D, Stewart L \& Shekelle P: Implementing PRISMA-P: recommendations for prospective authors. Systematic Reviews2016 5:15.

13. Software Cochrane Reviews RevMan 5.4. :https://training.cochrane.org/online-learning/core. Acessed 20 Nov 2020

14. Poier D, Rodrigues Recchia D, Ostermann T, Büssing A. A Randomized Controlled Trial to Investigate the Impact of Tango Argentino versus Tai Chi on Quality of Life in Patients with Parkinson Disease: a Short Report. 2019; doi: 10.1159 / 000500070.

15. Skogar T, Borg A, Larsson B, Robertsson L, Andersson L, Andersson L, et al. " Effects of Tactile Touch on pain, sleep and health related quality of life in Parkinson's disease with chronic pain": a randomized, controlled and prospective study. 2013; doi: 10.1016 / j.eujim.2012.10.005

16. Theodoros DG, Hill AJ, Russell TG. Clinical and Quality of Life Outcomes of Speech Treatment for Parkinson's Disease Delivered to the Home Via Telerehabilitation: a Noninferiority Randomized Controlled Trial. 2016; doi: 10.1044 / 2015_AJSLP-15-0005.

17. Ribas CG, Alves da Silva L, Corrêa MR, Teive HG, Valderramas S. Effectiveness of exergaming in improving functional balance, fatigue and quality of life in Parkinson's disease: a pilot randomized controlled trial. 2017; doi: 10.1016 / j.parkreldis.2017.02.006.

18. Hoehn MM, Yahr MD. Parkinsonism: onset, progression, and mortality. 1967; doi: 10.1212 / wnl.50.2.318.

19. Peto V, Jenkinson C, Fitzpatrick R, Greenhall R. The development and validation of a short measure of functioning and well being for individuals with Parkinson's disease. 1995; doi: 10.1007 / BF02260863.

20. de Boer AG, Wijker W, Speelman JD, de Haes JC. Quality of life in patients with Parkinson's disease: development of a questionnaire. 1996; doi: 10.1136 / jnnp.61.1.70.

21. Ware JEJ, Sherbourne CD. The MOS 36-item short-form health survey (SF-36). I. Conceptual framework and item selection. Med Care. 1992; 30:473-83.

22. Sharma, Neha; Srivastav, Adarsh Kumar; SamuelAMUEL AJ. Ensaio clínico randomizado: padrão ouro de desenhos experimentais - importância, vantagens, desvantagens e preconceitos. 2020; doi: 10.17267/2238-2704rpf.v10i3.3039.

23. Pequeno NPF, Cabral NL de A, Marchioni DM, Lima SCVC, Lyra C de O. Quality of life assessment instruments for adults: a systematic review of population-based studies. 2020; doi: 10.1186/s12955020-01347-7.

24. Sjödahl Hammarlund C, Westergren A, Åström I, Edberg A-K, Hagell P. The Impact of Living with Parkinson's Disease: Balancing within a Web of Needs and Demands. 2018; doi: 10.1155/2018/4598651.

25. Tavares DM dos S, Matias TGC, Ferreira PC dos S, Pegorari MS, Nascimento JS, Paiva MM de, et al. Qualidade de vida e autoestima de idosos na comunidade. 2016; doi: 10.1590/1413812320152111.03032016. 
26. Abell R V, Baird AD, Chalmers KA. Group singing and health-related quality of life in Parkinson's disease. 2017; doi: 10.1037 / hea0000412.

\section{Figures}

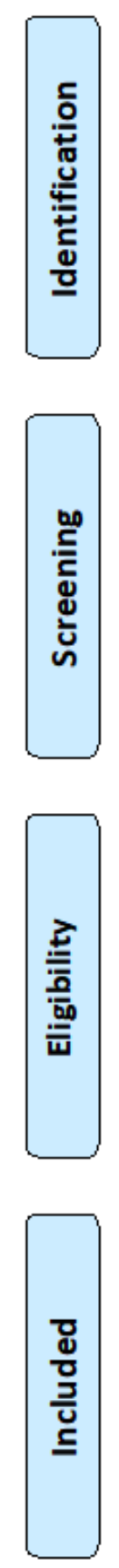

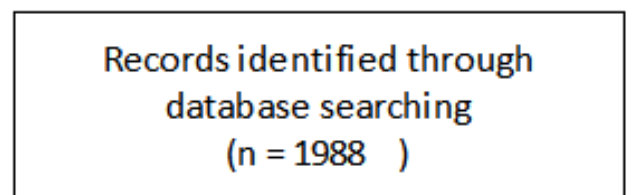

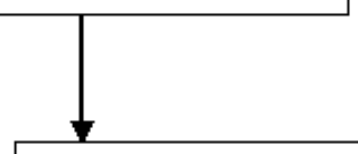

Additional records identified through other sources (Manual Search) $(n=2)$

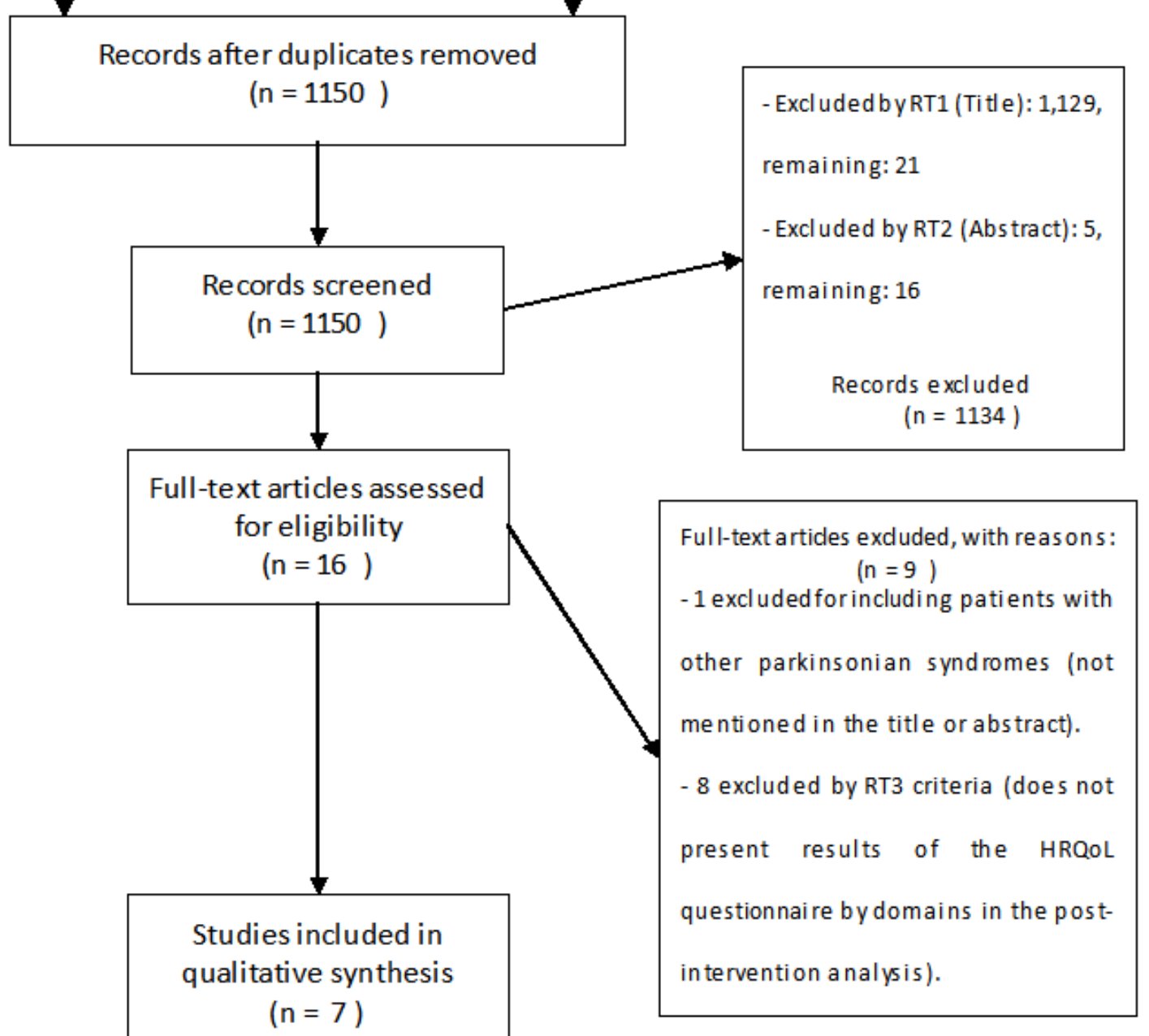

\section{Figure 1}

Flow Diagram 
Random sequence generation (selection bias)

Allocation concealment (selection bias)

Blinding of participants and personnel (performance bias)

Blinding of outcome assessment (detection bias)

Incomplete outcome data (attrition bias)

Selective reporting (reporting bias)
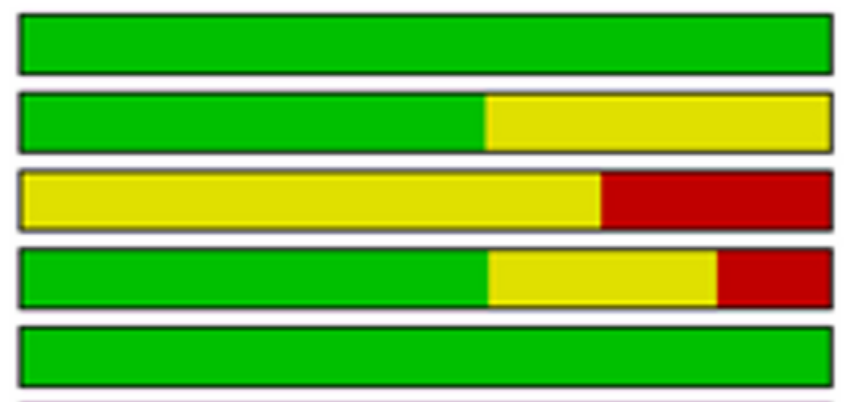

\section{Other bias}
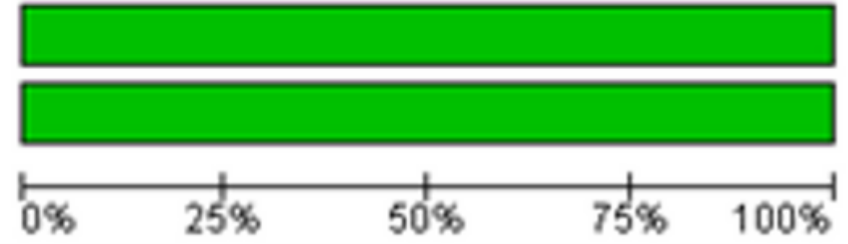

Low risk of bias

Unclear risk of bias

High risk of bias

Figure 2

Risk of Bias (Cochrane Colaboration)

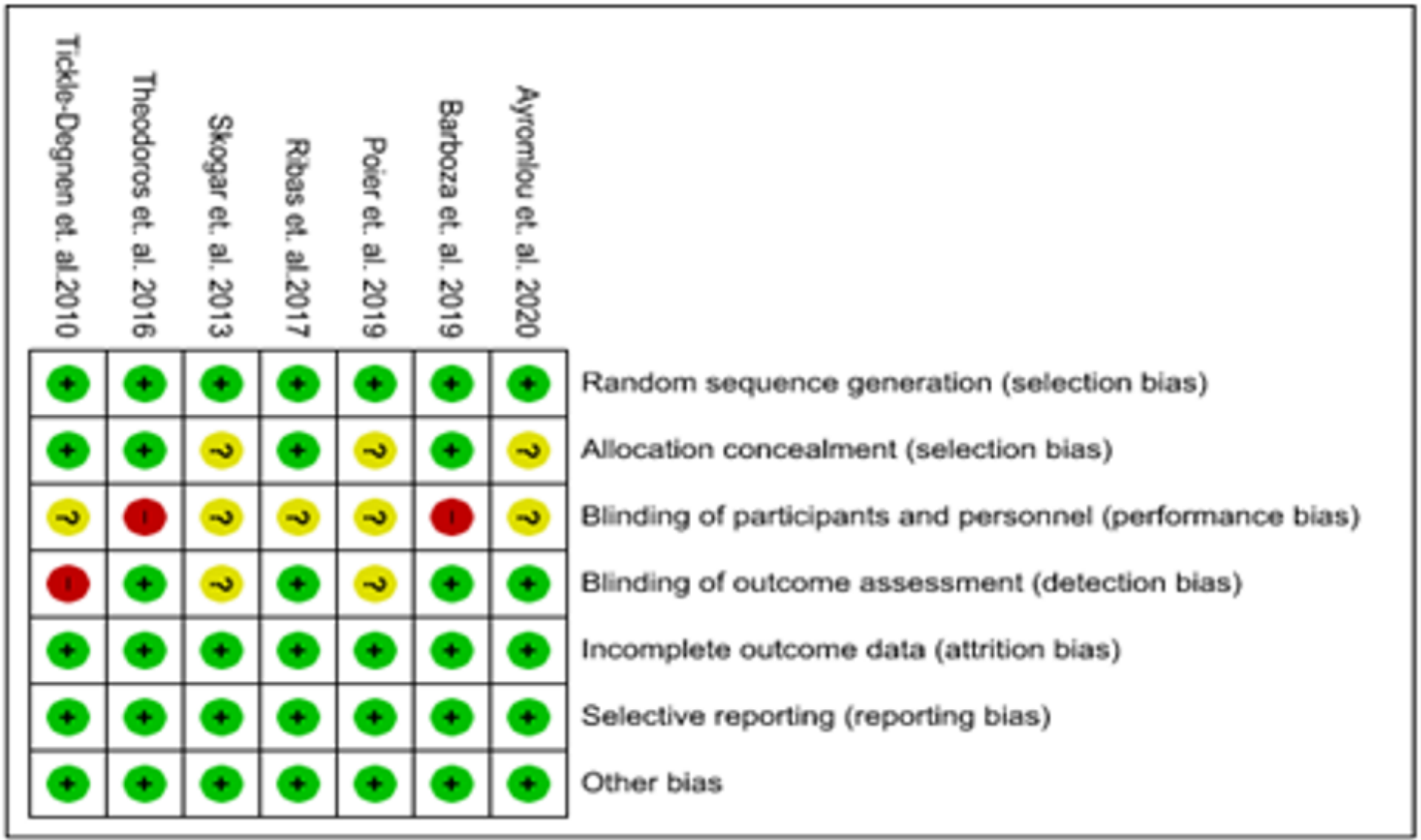

Figure 3

Risk of Bias (Cochrane Colaboration) 


\section{Supplementary Files}

This is a list of supplementary files associated with this preprint. Click to download.

- Reference14.pdf

- Reference15.pdf

- Reference16.pdf

- Reference17.pdf

- Reference2.pdf

- Reference5.pdf

- Reference8.pdf 